Pesq. Vet. Bras. 37(10):1057-1063, outubro 2017 DOI: $10.1590 / \mathrm{S} 0100-736 \mathrm{X} 2017001000003$

\title{
Mycoplasma hyorhinis infection in early cases of mycoplasmal pneumonia in swine and evaluation of diagnostic assays ${ }^{1}$
}

\author{
Carlos E.R. Pereira ${ }^{2}$, Fabio A. Vannucci ${ }^{3}$, Michelle de P. Gabardo ${ }^{2}$, Lucas F. dos \\ Santos $^{3}$, Nelson Mores ${ }^{4}$ and Roberto M.C. Guedes ${ }^{2 *}$
}

\begin{abstract}
Pereira C.E.R., Vannucci F.A., Gabardo M.P., Santos L.F., Mores N. \& Guedes R.M.C. 2017. Mycoplasma hyorhinis infection in early cases of mycoplasmal pneumonia in swine and evaluation of diagnostic assays. Pesquisa Veterinária Brasileira 37(10):1057-1063. Setor de Patologia Veterinária, Escola de Veterinária, Universidade Federal de Minas Gerais, Av. Antônio Carlos 6627, Pampulha, Belo Horizonte, MG 31270-901, Brazil. E-mail: guedesufmg@gmail.com

Mycoplasmal pneumonia is an important disease in the pig industry. Due to the controversial role of Mycoplasma hyorhinis in this disease, confirmation of the presence of this bacterium and the identification of its roles in respiratory disease remain major challenges. The objectives of this study were to evaluate the presence of $M$. hyorhinis in early cases of mycoplasmal pneumonia and to determine the usefulness of fluorescent in situ hybridization (FISH) for the diagnosis of respiratory mycoplasmosis in naturally infected pigs. Ninety M. hyopneumoniae and/or M. hyorhinis-infected lung tissue samples based on diagnostic mosaic (DM) were used. The average age of the animals was 116 and 57 days $(\mathrm{P}<0.01)$ for groups 1 (positive-M. hyopneumoniae only) and 2 (positive-M. hyorhinis only), respectively. These findings suggest that development of lesions caused by $M$. hyorhinis occurs earlier than for M. hyopneumoniae. Using the DM as the gold standard, the sensitivity and specificity of FISH for M. hyopneumoniae were 75 and $100 \%$, respectively, and were 40 and $73.3 \%$ for the immunohistochemistry (IHC). The sensitivity and specificity of FISH for M. hyorhinis were 76.7 and $100 \%$, respectively. These findings demonstrate that FISH can be a useful tool for diagnosing mycoplasmosis. Viral antigens (PCV2 or influenza A) were detected in $53.3 \%(16 / 30)$ of the samples in group 2 (M. hyorhinis-PCR positive) and $13.3 \%(4 / 30)$ of the samples in group 1 (M. hyopneumoniae-PCR positive). This finding indicates that the association of M. hyorhinis and viral infection in nursery pigs likely starts due to a viral immunosuppressive condition.
\end{abstract}

INDEX TERMS: Mycoplasma hyorhinis, mycoplasmal pneumonia, swine, Mycoplasma hyopneumoniae, fluorescent in situ hybridization, immunohistochemistry.

RESUMO.- [Infecção por Mycoplasma hyorhinis em casos precoces de pneumonia micoplásmica em suínos e comparação entre técnicas diagnósticas.] A pneumonia micoplásmica causada por bactérias do gênero Mycoplasma

\footnotetext{
${ }^{1}$ Received on March 23, 2016.

Accepted for publication on January 31, 2017.

${ }^{2}$ Departamento de Clínica e Cirurgia, Escola de Veterinária, Universidade Federal de Minas Gerais (UFMG), Av. Antônio Carlos 6627, Pampulha, Belo Horizonte, MG 31270-901, Brazil. *Corresponding author: guedesufmg@gmail.com

${ }^{3}$ Laboratório de Microbiologia Veterinária, Microvet, Rua Joaquim Lopes de Faria 730, Santo Antônio, Viçosa, MG 36570-000, Brazil.

${ }^{4}$ Embrapa Suínos e Aves, Rodovia BR-153 Km 110, Distrito de Tamanduá, Cx. Postal 21, Concórdia, SC 89700-000, Brazil.
}

é uma enfermidade de grande importância para indústria suinícola, sendo ainda controverso o papel desempenhado por Mycoplasma hyorhinis nessa doença. A confirmação da presença dessas bactérias bem como a identificação de seus papéis em doenças respiratórias continua sendo um grande desafio. Os objetivos desse estudo foram comparar diferentes técnicas, em especial a de hibridização fluorescente in situ (FISH), para diagnóstico de micoplasmoses respiratória em suínos naturalmente infectados e avaliar a presença do M. hyorhinis em casos precoces de pneumonia micoplásmica. Foram utilizadas 90 amostras de tecido pulmonar infectado para cada um ou ambos os agentes $(M$. hyopneumoniae e M. hyorhinis) determinados pelo mosaico de diagnóstico (sinais clínicos, lesões macroscópicas e mi- 
croscópicas e pela PCR). No grupo de animais positivos pela PCR apenas para M. hyorhinis (Grupo 2) a média da idade foi de 57,32 dias e no grupo apenas positivo para M. hyopneumoniae (Grupo 1) a média foi de 116,31 dias $(\mathrm{P}<0,01)$. Estes achados sugerem que a colonização e o aparecimento de lesões causadas pelo M. hyorhinis seja mais precoce do que aquelas causadas pelo $M$. hyopneumoniae. As alterações microscópicas foram estatisticamente $(\mathrm{P}<0,01)$ mais intensas no grupo 1 do que no grupo 2. Usando o mosaico de diagnóstico como padrão ouro, a sensibilidade e especificidade na FISH para M. hyopneumoniae foi de 75 e 100\%, respectivamente, e 40 e 73,3\%, na imuno-histoquímica. A sensibilidade e especificidade da FISH para M. hyorhinis foi de 76,7 e 100\%. Esses valores demonstram que a FISH pode ser uma ferramenta útil para diagnóstico de micoplasmoses. Foi detectada a presença de agentes virais (PCV2 ou influenza) em 53,3\% das amostras do grupo 2 (M. hyorhinis) e em 13,3\% das amostras do grupo 1 (M. hyopneumoniae).

TERMOS DE INDEXAÇÃO: Mycoplasma hyorhinis, pneumonia micoplásmica, suínos, Mycoplasma hyopneumoniae, hibridização in situ fluorescente, imuno-histoquímica.

\section{INTRODUCTION}

Several causative agents of pneumonia in swine may act alone or synergistically to cause a syndrome known as Porcine Respiratory Disease Complex (PRDC) (Sorensen et al. 2006). Among the major agents involved in this complex are Mycoplasma hyopneumoniae, Influenza A virus, Porcine Circovirus type 2 (PCV2) and Porcine Respiratory and Reproductive Syndrome Virus (PRRSV). Secondary contamination by bacterial pathogens aggravates the condition (Choi et al. 2003).

As a respiratory pathogen, $M$. hyopneumoniae has great relevance due to its difficulty to control and its kinetics of infection. Generally, this microorganism causes a chronic but mild pneumonia known as mycoplasmal pneumonia. Its immunosuppressive characteristics make the animal more vulnerable to infection by other pathogens, leading to signs of enzootic pneumonia (EP) (Thacker \& Minion 2012).

Mycoplasma hyorhinis is a saprophytic inhabitant of the swine respiratory tract, but it is also incriminated as a causative agent of polyserositis, arthritis, otitis and occasionally pneumonia. The conditions that trigger the pathogenesis of this process are not known (Rovira et al. 2010). When associated with pulmonary disease, pneumonic lesions observed in M. hyorhinis-affected pigs are similar to those caused by M. hyopneumoniae (Lin et al. 2006).

Swine are susceptible to infection with $M$. hyopneumoniae at any stage of life, however, the high concentration of maternal antibodies during the first days of life and the long incubation period of the disease make the clinical signs and lesions, in general, appear during the rearing phase. In recent years, with the growing interest and investigation into the diagnosis of influenza A virus, pigs positive for this virus in early nursery have presented with similar macroscopic lesions to mycoplasmal pneumonia. Lungs with cranio-ventral consolidation associated with histological changes characterized by BALT hyperplasia are sug- gestive of infection caused by Mycoplasma spp. (Lin et al. 2006). Thus, suspicions of the involvement of $M$. hyorhinis in early cases of mycoplasmal pneumonia have prospered. On the other hand, little is known about the pathogenic potential of this microorganism when in association with certain viral agents, particularly with those capable of causing immunosuppression (Chen et al. 2016). For this reason, it is reasonable to suppose that $M$. hyorhinis may play a relevant role in the genesis of these alterations, mainly when associated with immunosuppressive factors.

Bacterial isolation is the gold standard for the diagnosis of mycoplasmosis (Thacker \& Minion 2012). However, the fastidious properties of $M$. hyopneumoniae are different than the rapid growth of other species of the same genus (e.g. M. hyorhinis). Therefore, the search for diagnostic methods with high sensitivity such as PCR is an interesting option (Calsamiglia et al. 1999, Stakenborg et al. 2006). Alternatively, other techniques can be used such as immunohistochemistry and, more recently, fluorescence in situ hybridization (FISH). This technique has the advantage of locating the agent in the tissue associated with the lesions; however, little is known about its sensitivity and specificity (Erlandson et al. 2005).

The scarcity of information about the usefulness of the different diagnostic techniques for Mycoplasma spp. in swine, as well as the scattered reports emphasizing the role of M. hyorhinis in the genesis of lung diseases in swine, represent a lack of essential data. Thus, the present study compares the sensitivity and specificity of different diagnostic techniques for respiratory mycoplasmosis in naturally infected swine and evaluates the presence of $M$. hyorhinis in early cases of mycoplasmal pneumonia.

\section{MATERIALS AND METHODS}

Samples. Ninety lung tissue samples from January 2011 to July 2013, originating from the major swine producing regions of Brazil (South, Southeast and Midwest), were selected. Tissue fragments were obtained from animals with clinical signs of respiratory disease, macroscopic lesions and positive reaction by duplex PCR techniques (M. hyopneumoniae and M. hyorhinis). The criteria of selection for inclusion in the study were positivity for at least one of the aforementioned agents by PCR and the presence of microscopic lesions suggestive of mycoplasmosis. Based on the duplex PCR, 30 positive samples for M. hyopneumoniae (group 1), 30 positive for M. hyorhinis (group 2) and 30 positive for both agents (group 3) were selected. Information relative to the age and clinical history was obtained from the diagnostic records of all animals involved in the present study.

Duplex-PCR. The total DNA from lung fragments and bronchial swabs was extracted from pneumonic areas using the PrepMan (Applied Biosystems Carlsbad, CA, USA) method, following the manufacturer's recommendations. The DNA concentration was analyzed by an Ultrospec 1100 pro (UV/ visible spectrophotometer Amersham Biosciences, Cambridge, England, UK) spectrophotometer, using a rate of $100 \mu \mathrm{L}$ to standardize the DNA concentration to $2 \mathrm{ng} / \mu \mathrm{L}$. For the detection of the Mycoplasmas, the initiator oligonucleotides that amplify the 16 s portion of the rRNA were used: 5'-CGGGATGTAGCAATACTTCAG-3' for M. hyorhinis and 5'-TTCAAAGGAGCCTTCAAGCTTC-3' for M. hyopneumoniae and a reverse oligonucleotide 5'-AGAGGCATGATTTGACGTC-3', common to all the initiators present in the reaction. These initiators am- 
plified a fragment of 1129 base pairs (bp) for M. hyorhinis and $1000 \mathrm{bp}$ for M. hyopneumoniae within the coding region of the $16 \mathrm{~S}$ rRNA gene (Stakenborg et al. 2006). Total DNA was subjected to PCR using a final volume of $25 \mu \mathrm{L}$. With the exception of the DNA, all reagents were combined in a mix containing 10X PCR buffer, $3 \mathrm{mM} \mathrm{MgCl}, 1 \mathrm{mM}$ dNTP mix, 1 pmol of the sense initiator, antisense $1 \mathrm{pmol}$, qs $\mathrm{H}_{2} \mathrm{O}$ Milli-Q $25 \mu \mathrm{L}$ and 1 unit of Taq polymerase (Invitrogen Life Technologies, Carlsbad, CA, USA). The mixture was dispensed into $200 \mu \mathrm{L}$ microtubes and mixed slowly. The PCR reactions were performed in a PXE 0.2 THERMO (Thermo Electron Corporation) thermocycler with an initial temperature of 94 ${ }^{\circ} \mathrm{C}$ for 1 minute, followed by 30 cycles of 30 seconds at $94{ }^{\circ} \mathrm{C}, 15$ seconds at $54.6^{\circ} \mathrm{C}$, and 1 minute at $68^{\circ} \mathrm{C}$ with an extension of 10 minutes at $72^{\circ} \mathrm{C}$ (Stakenborg et al. 2006).

Histopathology. Lung fragments from regions adjacent to the samples used for the PCR were fixed in 10\% buffered formalin (pH 7.2), routinely processed for histopathology and embedded in paraffin. Six sections of $4 \mu \mathrm{m}$ thickness of each fragment were prepared. Five sections on silanized slides were used for immunohistochemical staining using antibodies against $M$. hyopneumoniae, influenza A virus, PCV2 and fluorescence in situ hybridization (FISH) for M. hyopneumoniae and M. hyorhinis, as described herein. One section not fixed on a silanized slide was hematoxylin and eosin (HE) stained for routine histologic evaluation. Microscopic lesions typical of mycoplasmal pneumonia were graded as follows: zero (0), absence of lesions; one (1), discrete peribronchial, peribronchiolar and perivascular diffuse lymphocytic infiltrate, and discrete hyperplasia of type II pneumocytes; two (2), moderate peribronchial, peribronchiolar and perivascular diffuse lymphocytic infiltrate, moderate hyperplasia of type II pneumocytes and discrete BALT hyperplasia; three (3), intense peribronchial, peribronchiolar and perivascular diffuse lymphocytic infiltrate, intense hyperplasia of type II pneumocytes and moderate BALT hyperplasia; and four (4) intense and diffuse BALT hyperplasia (Hansen et al., 2010). As previously mentioned, only PCR positive samples for at least one of the agents (M. hyopneumoniae and/or M. hyorhinis) associated with histological lesions (grade 1 to 4) were included in this study. A pathologist blinded for the experimental groups performed the histological grading of all tissue samples.

Fluorescence in situ hybridization. The FISH procedure was performed according to Boye et al. (2001), using individual probes for the detection of the Mycoplasmas, with oligonucleotides sequences that target the 16 s portion of the rRNA: 5'CCGTCAAGACTAGAGCAT 3' for $M$. hyopneumoniae and 5'GCTGTGAAGCTCCTTTCT 3 ' for $M$. hyorhinis. Tissue sections were deparaffinized by heating in an incubator at $65^{\circ} \mathrm{C}$, immersed in xylene and hydrated in decreasing ethanol solutions and distilled water for 5 minutes. Hybridization was performed in hybridization chambers with slides mounted in a coverplate and incubated with $100 \mathrm{ml}$ of hybridization buffer (100 mM Tris, pH 7.2, $0.9 \mathrm{M} \mathrm{NaCl}, 0.1 \%$ of sodium dodecyl sulfate) and $500 \mathrm{ng}$ of probe at $37^{\circ} \mathrm{C}$ for 16 hours. After this period, the preparations were washed three times with pre-warmed hybridization buffer $\left(37^{\circ} \mathrm{C}\right)$ and later three more times with pre-warmed washing buffer $\left(37^{\circ} \mathrm{C}\right)(100 \mathrm{mM}$ Tris, $\mathrm{pH}$ $7.2,0.9 \mathrm{M} \mathrm{NaCl}$ ). The preparations were finally washed with distilled water and dried in an incubator at $37^{\circ} \mathrm{C}$. The entire procedure was performed without direct light. Subsequently, the slides were examined under a fluorescence microscope (Olympus, AX70, Japan) with a filter cube for the fluorochrome Cy3 using immersion objectives with $40 \mathrm{X}$ and $100 \mathrm{X}$ magnification and immersion oil for fluorescence microscopy.

Lung paraffin blocks positive for $M$. hyopneumoniae and $M$. hyorhinis, kindly provided by Embrapa Suínos e Aves (CNPSA) and by Dr. Tim Kare Jensen from the Danish National Institute (Danish
Technical University), respectively, were used as controls for the FISH technique. Samples were considered positive when there was evident detection of a fluorescent signal of the agent in the tissue and negative in the absence of a relevant sign.

Mycoplasma hyopneumoniae immunohistochemistry. The immunohistochemistry technique for $M$. hyopneumoniae was performed according to the protocol used by Lorenzo et al. (2006). The Streptavidin labelled with Peroxidase technique (LSAB Kit, Dako), antigen retrieval with microwave and pepsin, and polyclonal primary antibody against the P36 protein of $M$. hyopneumoniae were used. PBS (pH 7.2) was used for the washes, aminoethyl carbazole (AEC) as the chromogen and Mayer's Hematoxylin for counterstaining.

PCV2 and Influenza immunohistochemistry. Similar to the prior technique, the immunohistochemistry for PCV2 and Influenza A virus was performed using the Labelled streptavidin-biotin technique (LSAB kit, Dako). Proteinase K for antigen retrieval and the following primary antibodies were used: rabbit anti-PCV2 polyclonal (Souza et al. 2008) and anti-Influenza A virus nucleoprotein monoclonal antibodies (Vincent et al. 1997). PBS (pH 7.2) was used for the washes, aminoethyl carbazole (AEC) as the chromogen and Mayer's Hematoxylin for counterstaining.

Statistical analysis. The sensitivity, specificity, positive predictive value and negative predictive value were calculated for FISH for M. hyopneumoniae and M. hyorhinis and IHC for M. hyopneumoniae considering the diagnostic mosaic previously described as the gold standard.

The diagnostic mosaic considered a sample positive when there were (i) respiratory clinical signs; (ii) macroscopic and microscopic lesions suggestive of mycoplasmosis and; (iii) detection of the agent by PCR. The mean age of animals in groups 1 and 2 were compared using Student's t-test. The microscopic lesions of groups 1, 2 and 3 were compared by the Kruskal-Wallis non-parametric method. The association with viral agents (PCV2 and Influenza) detected in groups 1, 2 and 3 was evaluated by chi-square test. The analyses were performed using the statistical analysis system (SAS) software version 9.2.

\section{RESULTS}

\section{Age and histopathology}

Four samples of group 1 and two of group 2 had no age information and were excluded from this analysis. Group 3 was not included in this comparison as the animals were infected with both agents according to PCR.

The average age of pigs positive for Mycoplasma hyopneumoniae (group 1) was 116 days, ranging from 40 to 180 days. The mean age of animals in group 2, PCR positive for M. hyorhinis only, was 57 days, ranging from 28 to 110 days (Table 1). The animals infected with M. hyorhinis were significantly younger $(\mathrm{P}<0.01)$ than the animals infected with M. hyopneumoniae.

Histological findings are summarized in Table 1. Animals in group 1 ( $M$. hyopneumoniae) had more severe lesions than in group 2 (Mycoplasma hyorhinis) $(\mathrm{P}<0.05)$.

\section{FISH and IHC for Mycoplasma hyopneumoniae}

Samples were considered positive by FISH when the fluorescence emission in the form of small granules was observed with a linear distribution on the surface of the epithelium of bronchi and bronchioles and diffusely in the exudate present in the airway lumens (Fig.1). Larger granules, corresponding to tissue autofluorescence, were observed in the lamina propria (Fig.2). Forty-five samples 
Table 1. Average age (mean \pm SD) of the animals, immunohistochemistry results for PCV2 and Influenza A, and intensity of microscopic lesions in the PCR-positive samples for Mycoplasma hyopneumoniae (group 1), for Mycoplasma hyorhinis (group 2) or both (group 3)

\begin{tabular}{lccccc}
\hline & Age (mean \pm SD) & Histologic lesions & PCV2 $(+)$ & Influenza A $(+)$ & Virus(+) \\
\hline Group 1 & $116,31 \pm 6,14 \mathrm{~A}$ & $2,37 \pm 0,17 \mathrm{~A}$ & $0 / 30 \mathrm{~A}$ & $4 / 30 \mathrm{~A}$ & $4 / 30 \mathrm{~A}$ \\
Group 2 & $57,32 \pm 5,92 \mathrm{~B}$ & $1,63 \pm 0,17 \mathrm{~B}$ & $6 / 30 \mathrm{~B}$ & $14 / 30 \mathrm{~B}$ & $16 / 30 \mathrm{~B}$ \\
Group 3 & - & $2,17 \pm 0,17 \mathrm{AB}$ & $0 / 30 \mathrm{~A}$ & $10 / 30 \mathrm{AB}$ & $10 / 30 \mathrm{AB}$
\end{tabular}

Different capital letters in the same column indicate a statistically significant difference at $\mathrm{P}<0.05$.

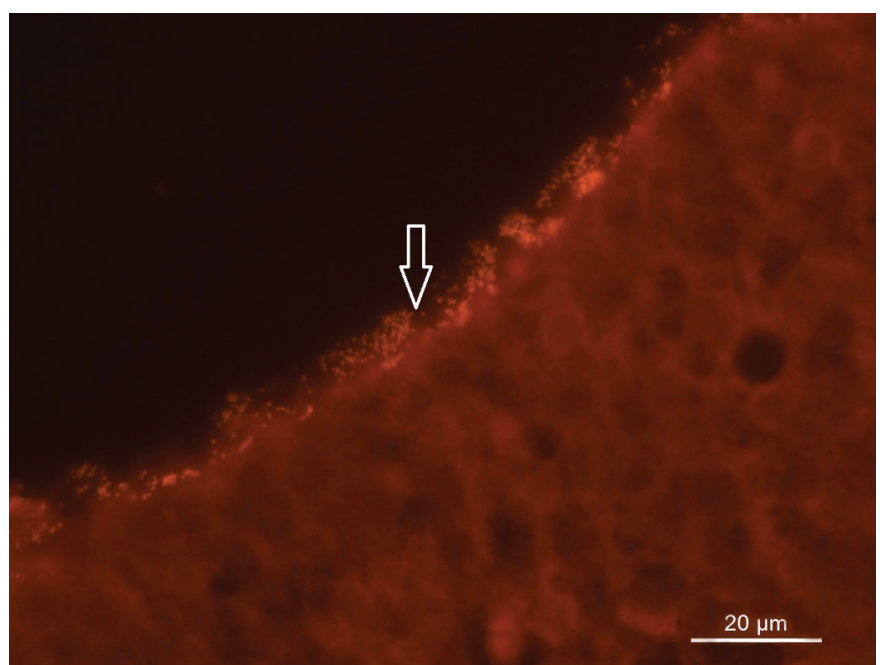

Fig.1. FISH, Mycoplasma hyopneumoniae labeling in the lung of pigs from group 1. Bronchus: The fluorescent signal on the epithelial surface (arrow) represents $M$. hyopneumoniae labeling. (CY3, 1000x).

were positive for $M$. hyopneumoniae by the FISH technique of the 60 positive for this agent in the diagnostic mosaic (groups 1 and 3), with a sensitivity of $75 \%(45 / 60)$. In the 30 negative samples for $M$. hyopneumoniae (group 2) using the diagnostic mosaic, there was no fluorescence signal by the FISH technique for $M$. hyopneumoniae in any of the studied samples (Table 1), allowing us to conclude that FISH was highly (30/30) specific (100\%). The Positive Predictive Value (PPV) was 100\% (45/45), indicating that all of the samples positive by FISH are truly positive when considering the diagnostic mosaic. The Negative Predictive Value (NPV) was 66.6\% (30/45), showing that of the samples considered negative by FISH, one-third were false negatives when the diagnostic mosaic was considered. In cases where there was a Mycoplasma co-infection (group 3 ) by PCR, $M$. hyopneumoniae-positive cases were less diagnosed $(66.6 \%, 20 / 30)$ when compared to group 1 , which had $83.3 \%$ (25/30) positivity by the FISH technique.

Positive immunostaining by IHC technique for $\mathrm{Myco}$ plasma hyopneumoniae antigens was observed on the surface of the respiratory epithelium (Fig.3) and in the exudate located in the interior of the airways. Comparing to the diagnostic mosaic, the IHC technique had a sensitivity of $40 \%$, because 24 of the 60 PCR positive animals for $M$. hyopneumoniae (groups 1 and 3 ) had immunostaining. The specificity of the technique was measured by analyzing the samples of group 2 (M. hyorhinis-PCR positive), resulting in a percentage of $73.3 \%$, which corresponds to the absence of immunostaining in 22 of the 30 samples. The PPV was $75 \%(24 / 32)$ and the NPV was $37.9 \%$ (Table 1). When the sensitivity of the IHC technique was evaluated separately in groups 1 and 3, it resulted in percentages of $46.7 \%$ and $33.3 \%$, respectively (Table 1 ).

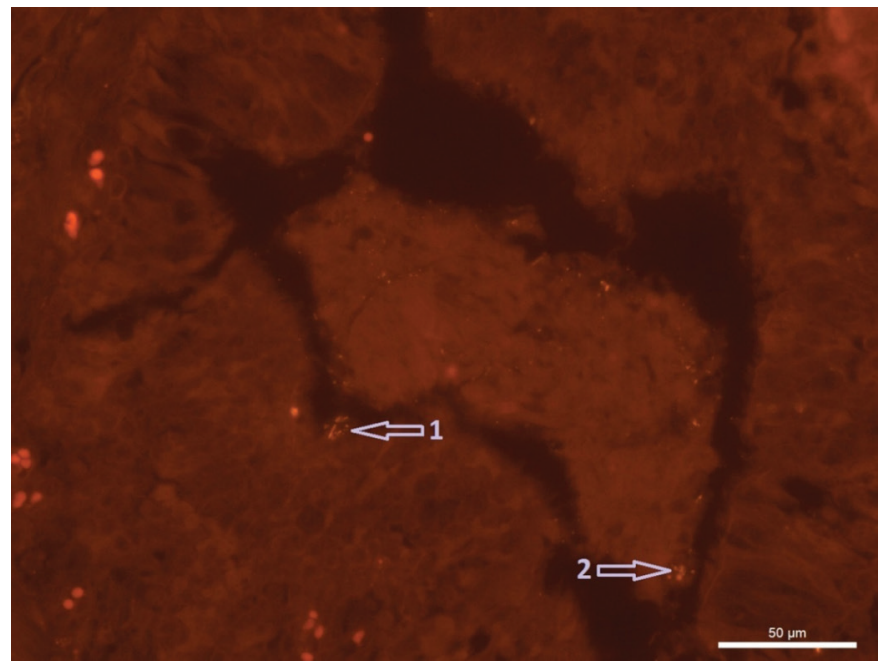

Fig.2. FISH, Mycoplasma hyorhinis labeling in the lung of a pig from group 2. Bronchioles: fluorescent granular structures forming small colonies adhered to the epithelium (arrow 1) and granular structures in the exudate of the lumen (arrow 2) (CY3, 400x).

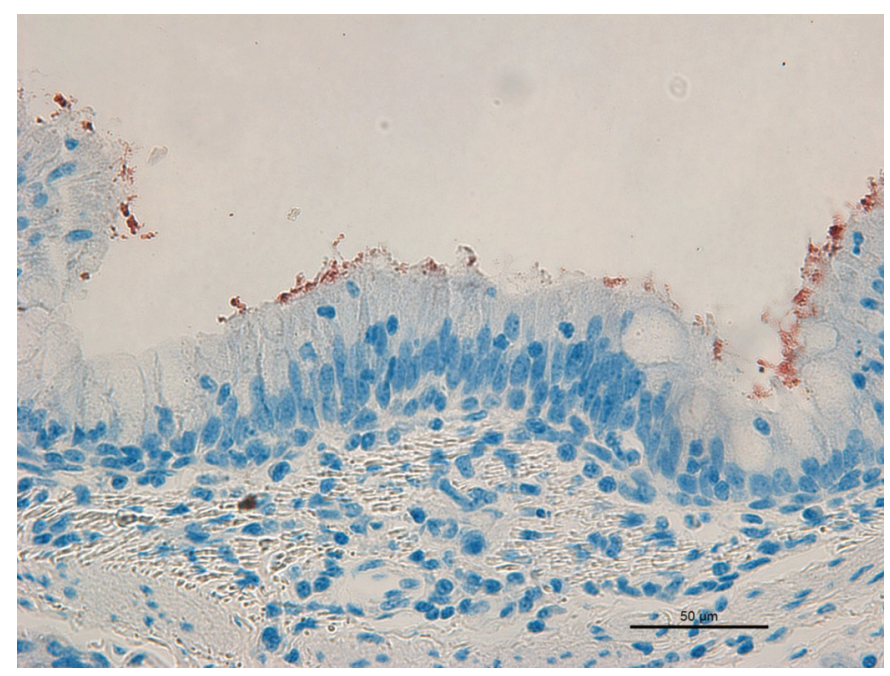

Fig.3. IHC, Mycoplasma hyopneumoniae, lung of pig. Group 1. Bronchus. Red immunostaining on the surface of the respiratory epithelium (AEC, hematoxylin, 400x). 


\section{FISH for Mycoplasma hyorhinis}

The characteristics of the fluorescence emitted by $M$. hyorhinis were similar to those emitted by M. hyopneumoniae, however, the amount of these bacteria adhering to the epithelium of the bronchi and bronchioles was scarce and detected in a greater amount in the exudate of the airways (Fig.2). The predictive values from the FISH technique for $M$. hyorhinis were similar to those of $M$. hyopneumoniae (Table 1), with a sensitivity of $76.7 \%(46 / 60)$, specificity of $100 \%$ (30/30), PPV of $100 \%(46 / 46)$ and NPV of $68.18 \%$ (30/44). Similar to M. hyopneumoniae, in samples PCR-positive for both agents (group 3), the FISH technique had lower sensitivity $(70 \%, 21 / 30)$ compared to group 2 , which was $83.3 \%(25 / 30)$.

\section{Immunohistochemistry for PCV2 and Influenza A virus}

All samples of the three groups were tested by IHC for PCV2 and Influenza A virus. The samples positive for PCV2 had immunostaining in the cytoplasm and in the nuclear membrane of histiocytes, especially in peribronchial and peribronchiolar regions. The immunolabeling for Influenza A virus was located in the cytoplasm of the cells of the bronchial and bronchiolar epithelium and of the bronchial glands. In group 1, four (13.3\%) samples were immunoreactive for the Influenza $\mathrm{A}$ virus and none were positive for PCV2. Group 2 had 14 (46.67\%) samples positive for influenza A virus and six (20\%) positive for PCV2, with 16 samples (53.3\%) positive for at least one of the viral agents (Table 1). In group 3 there was no detection of PCV2, while $10(33.3 \%)$ samples were positive for Influenza A virus.

\section{DISCUSSION}

In the present study, the average age of the animals affected by Mycoplasma hyorhinis (group 2) was significantly lower than those infected with Mycoplasma hyopneumoniae (group 1). Although pigs are susceptible at any age, it is well known that M. hyopneumoniae infection occurs most often in the nursery phase and, due to its long incubation period, clinical signs and lesions will appear later, in the grower and finisher stages. Experimental studies (Sorensen et al. 1997, Deblanc et al. 2013) indicate that the onset of the clinical signs is one week after inoculation, reaching the greatest severity after the 20th day. In vitro, M. hyorhinis growth is faster than $M$. hyopneumoniae. Siqueira et al (2013) showed the presence of metabolic genes in the $M$. hyorhinis genome that are absent in M. hyopneumoniae, suggesting a possible factor associated with the in vitro growth of this species.

In group 2 (M. hyorhinis-PCR positive), more than $60 \%$ $(20 / 30)$ of the samples were IHC-positive for Influenza A and/or PCV2. When the study was conducted, there was no Influenza A vaccine approved or in use in Brazil. It is intriguing that influenza A virus was more frequently detected in M. hyorhinis-infected pigs, which makes us hypothesize that the virus might be involved in immunosuppressive conditions. Other immunosuppressive virus, such as PCV2 and PRRS, also affect nursery pigs. According to Clavijo et al. (2012), immunosuppressed animals are more prone to M. hyorhinis colonization and spread of the infec- tion. As a result, it appears that immunosuppressive factors at the beginning of the nursery period may contribute to infection with M. hyorhinis. Several studies have shown the association of M. hyorhinis with other infectious agents and immunosuppressive factors, such as stress (Kinne et al. 1991, Kawashima et al. 1996, Kawashima et al. 2007, Kixmoller et al. 2008), which enables M. hyorhinis to colonize and propagate in these individuals. Reinforcing the hypothesis that M. hyorhinis could be considered a secondary agent of pneumonic lesions, experimental studies involving this pathogen rarely showed areas of pneumonia, and when pneumonic lesions were present they were mild and affected a small percentage of the inoculated animals (Poland et al. 1971, Lin et al. 2006).

The present study demonstrated a correlation between animals PCR-positive for M. hyorhinis (group 2) and positive for the Influenza A virus and/or PCV2 (Table 1). It is noteworthy that the immunohistochemical tests were performed on lung fragments, which were not the optimal place to find PCV2. Furthermore, Influenza A infection is transient, so these results may have been underestimated. The location of $M$. hyorhinis identified by FISH was predominantly in the exudate of the airways (Fig.2). This fact suggests that this agent has a lower capacity to adhere to the cilia of the respiratory epithelium when compared to M. hyopneumoniae. This corroborates the hypothesis that $M$. hyorhinis is an opportunistic microorganism.

For the detection of $M$. hyopneumoniae, fluorescent signals were observed in microorganisms attached to the bronchi and bronchiole epithelium and in the exudate present in the lumen of airways. An ultra-structural study corroborated the findings of the present study (Blanchard et al. 1992). However, Doster \& Lin (1988) and Kwon \& Chae (1999), using ISH and IHC, also found M. hyopneumoniae in the interior of macrophages and type I pneumocytes. It is noteworthy that FISH is able to detect only viable microorganisms at the time of tissue fixation, which could at least partly justify this difference of observations and support the possibility that the bacteria was already dead in the interior of macrophages and type I pneumocytes.

All samples had histological changes of varying intensities, and they were characterized by inflammatory infiltrate, composed mainly of lymphocytes, adjacent to the bronchi, bronchioles and blood vessels and, in some cases, hyperplasia of lymphoid follicles (Doster \& Lin 1988, Sorensen et al. 1997, Lin et al. 2006). The average of the semi-quantification of histological lesions of group 1 was significantly higher than group 2. Group 3 did not differ significantly from the other two groups, indicating that the two agents did not act synergistically. In addition, Vicca et al. (2003) verified differences of pathogenicity among strains of M. hyopneumoniae and proposed a classification of low, medium and high virulence, indicating that the intensities of lesions may also vary depending on the strains present in the herd and at the time of infection.

Usually, BALT hyperplasia is observed in infections by Mycoplasma, although this alteration is not exclusive to these bacteria. According to Meisser and Ross (Meisser \& Ross 1991) these morphological manifestations could be 
related to a mitogenic protein found in the membranes of bacteria of the genus Mycoplasma. Similar lesions, although more discrete, were found in experimental studies with M. hyorhinis (Lin et al. 2006), but little is known about the actual relation of the agent to cases of pneumonia.

Because bacterial culture is a slow and frustrating method for the identification of bacteria from the genus Mycoplasma, the FISH technique is seen as a promising alternative that may contribute to the diagnosis and study of the pathogenesis of these species-specific agents. In our study, similar to observations by Boye et al. (2001), FISH had no cross-reaction between the two Mycoplasma species studied, showing $100 \%$ specificity.

The IHC technique for M. hyopneumoniae showed $73.3 \%$ specificity, because eight of the 30 samples from the M. hyopneumoniae PCR-negative group had positivity using a polyclonal primary antibody against the P36 protein of M. hyopneumoniae. All eight samples were positive by FISH for M. hyorhinis, indicating cross-reaction with M. hyorhinis (false positive). The quality of the antibody is a determining factor for the specific detection of an agent by IHC, because polyclonal antibodies may bind to other species of the genus (Cheik Saad Bouh et al, 2003). Interestingly, in group 3 there was a lower detection rate of $M$. hyopneumoniae by IHC (10/30) when compared to group $1(14 / 30)$. Group 3 had $93.3 \%$ positivity by FISH for M. hyorhinis or M. hyopneumoniae. Based on the possible cross-reaction, greater immunostaining in this group was expected.

The low sensitivity of IHC $(40 \%)$ compared to FISH (75\%) may be due to the different targets utilized by each technique. While antibodies for the IHC technique target the surface protein P36, FISH uses rRNA as a target. Regarding P36, Stipkovits et al. (1991) observed the expression of this protein in all field samples of M. hyopneumoniae tested. In contrast, Assunção et al. (2005) verified by immunoblotting that this protein was expressed in approximately $45 \%$ of $M$. hyopneumoniae field samples (8/18). Further studies on gene expression and M. hyopneumoniae strain heterogeneity are required to verify the presence of the P36 protein and its use as a marker in immunohistochemical techniques.

The sensitivity of the FISH technique ranged from $66.7 \%$ to $83.3 \%$ for M. hyopneumoniae and from $70 \%$ to $83.3 \%$ for M. hyorhinis. The lowest sensitivity was found in group 3, which had PCR-positive samples for both agents. The nature of the samples used for PCR or FISH, swabs and lung fragments, respectively, might explain this difference, because the tissue area examined by FISH is much smaller than the sample examined by PCR. Sorensen et al. (1997) evaluated different diagnostic techniques for M. hyopneumoniae and observed that there is a reduction in temporal sensitivity, declining progressively over time during the course of infection in all diagnostic techniques. The chronological effect could be linked to the amount of the agent in the tested sample, meaning that with the evolution of the process, a lower amount of Mycoplasma would be present, decreasing the sensitivity of the techniques (Thacker 2004).

FISH, with a sensitivity of $76.7 \%$ and specificity of
$100 \%$, allows visualization of viable agents within the lesions. It is important to mention that there are no anti- $M$. hyorhinis commercial antibodies available. The location of the microorganism is important because M. hyorhinis is a commensal of the swine respiratory tract. However, its detection does not always imply causality and should always be associated with macroscopic and microscopic lesions for a correct approach to the problems in the farm.

\section{CONCLUSIONS}

The results obtained from this study allowed us to conclude that the animals that were positive for Mycoplasma hyorhinis were younger than the animals infected with Mycoplasma hyopneumoniae.

A correlation between the FISH-positive samples for M. hyorhinis and IHC-positive samples for viral agents (Influenza A and PCV2) supports the hypothesis that $M$. hyorhinis is a secondary agent in pneumonic lesions in swine and should be considered in the differential diagnosis of M. hyopneumoniae, which causes identical macro and microscopic lesions in nursery pigs.

FISH demonstrated high specificity and fair sensitivity compared to PCR for the diagnosis of respiratory mycoplasmosis in swine.

IHC for M. hyopneumoniae had low sensitivity and specificity with false-positive results, possibly due to cross-reaction with M. hyorhinis.

The FISH technique constitutes a reliable tool for the diagnosis and study of the pathogenesis of these agents.

Declaration of conflicting interests.- The author(s) declare no potential conflicts of interest with respect to the research, authorship, and/or publication of this article.

Acknowledgements.- R. Guedes has a research fellowship from CNPq. This work was supported by funds from PRPq-UFMG. Preliminary results were presented as an oral presentation at the 23rd International Pig Veterinary Society, Cancun, 8th to 11th June 2014.

\section{REFERENCES}

Assunção P., De La Fe C., Ramirez A.S., González Llamazares O. \& Poveda J.B. 2005. Protein and antigenic variability among Mycoplasma hyopneumoniae strains by SDS-PAGE and Immunoblot. Vet. Res. Commun. 29:563-574.

Blanchard B., Vena M.M., Cavalier A., Le Lannic J., Gouranton J. \& Kobisch M. 1992. Electron microscopic observation of the respiratory tract of SPF piglets inoculated with Mycoplasma hyopneumoniae. Vet. Microbiol. 30:329- 341.

Boye M., Jensen T.K., Ahrens P., Hagedorn-Olsen T. \& Friis N.F. 2001. In situ hybridisation for identification and differentiation of Mycoplasma hyopneumoniae, Mycoplasma hyosynoviae and Mycoplasma hyorhinis in formalin-fixed porcine tissue sections. APMIS 9:656-664.

Calsamiglia M., Pijoan C. \& Trigo A. 1999. Application of a nested polymerase chain reaction assay to detect Mycoplasma hyopneumoniae from nasal swabs. J. Vet. Diagn. Invest. 11:246-251.

Cheik Saad Bouh K., Shareck F. \& Dea S. 2003. Monoclonal antibodies to Escherichia coli-expressed P46 and P65 membranous proteins for specific immunodetection of Mycoplasma hyopneumoniae in lungs of infected pigs. Clin. Diagn. Lab. Immunol. 10:459-468.

Chen D., Wei Y., Huang L., Wang Y., Sun J., Du W., Wu H. \& Liu C. 2016. Synergistic pathogenicity in sequential coinfection with Mycoplasma hyorhinis and porcine circovirus type 2. Vet. Microbiol. 182:123-130. 
Choi Y.K., Goyal S.M. \& Joo H.S. 2003. Retrospective analysis of etiologic agents associated with respiratory diseases in pigs. Can. Vet. J. 44:735-737.

Clavijo M.J., Bruner L., Olson S., Pearce D. \& Rovira A. 2012. Dynamics of infection of Mycoplasma hyorhinis in two commercial swine herds. In: Allen D. Leman Swine Conference Proceedings. 91-92.

Deblanc C., Robert F., Pinard T., Gorin S., Quéguiner S., Gautier-Bouchardon A.V., Ferré S., Garraud J.M., Cariolet R., Brack M. \& Simon G. 2013. Pre-infection of pigs with Mycoplasma hyopneumoniae induces oxidative stress that influences outcomes of a subsequent infection with a swine influenza virus of H1N1 subtype. Vet. Microbiol. 162:643-651.

Doster A.R. \& Lin B.C. 1988. Identification of Mycoplasma hyopneumoniae in formalin-fixed porcine lung, using an indirect immunoperoxidase method. Am. J. Vet. Res. 49:1719-1721.

Erlandson K.R., Evans R.B., Thacker B.J., Wegner M.W. \& Thacker E.L. 2005 Evaluation of three serum antibody enzyme-linked immunosorbent assays for Mycoplasma hyopneumoniae. JSHAP 13(4):198-203.

Hansen M.S., Pors S.E., Jensen H.E., Bille-Hansen V., Bisgaard M., Flachs E.M. \& Nielsen O.L. 2010. An investigation of the pathology and pathogens associated with porcine respiratory disease complex in Denmark. J. Comp. Pathol. 143:120-131.

Kawashima K., Yamada S., Kobayashi H. \& Narita M. 1996. Detection of porcine reproductive and respiratory syndrome virus and Mycoplasma hyorhinis antigens in pulmonary lesions of pigs suffering from respiratory distress. J. Comp. Pathol. 114(3):315-323.

Kawashima K., Katsuda K. \& Tsunemitsu H. 2007. Epidemiological investigation of the prevalence and features of postweaning multisystemic wasting syndrome in Japan. J. Vet. Diagn. Invest. 19(1):60-68.

Kinne J., Johannsen U., Neumann R., Mehlhorn G. \& Pfützner H. 1991. The pathology and pathogenesis of experimental Mycoplasma hyorhinis infection of piglets with and without thermomotoric stress. 1. Pathologico-anatomic, histologic and immunomorphologic study results. Zentr. Vet. Med. 38(4):306-320.

Kixmoller M., Ritzmann M., Eddicks M., Saalmüller A., Elbers K. \& Fachinger V. 2008. Reduction of PMWS-associated clinical signs and co-infections by vaccination against PCV2. Vaccine 26:3443-3451.

Kwon D. \& Chae C. 1999. Detection and localization of Mycoplasma hyopneumoniae DNA in lungs from naturally infected pigs by in situ hybridization using a digoxigenin-labeled probe. Vet. Pathol. 36:308-313.

Lin J.H., Chen S.P., Yeh K.S. \& Weng C.N. 2006. Mycoplasma hyorhinis in Taiwan: Diagnosis and isolation of swine pneumonia pathogen. Vet. Microbiol. 115:111-116.

Lorenzo H., Quesada O., Assunção P., Castro A. \& Rodríguez F. 2006. Cytoki- ne expression in porcine lungs experimentally infected with Mycoplasma hyopneumoniae. Vet. Immun. Immunopathol. 109:199-207.

Meisser S. \& Ross R.F. 1991. Interaction of Mycoplasma hyopneumoniae membranes with porcine lymphocytes. Am. J. Vet. Sci. 52:1497-1502.

Poland J., Edington N., Gois M. \& Betts A.O. 1971. The production of pneumonia with ou without pleurisy in gnotobiotic piglets with pure cultures of strain TR 32 of Mycoplasma hyorhinis. J. Hyg. Comb. 69:145-154.

Rovira A., Clavijo M.J. \& Oliveira S. 2010. Mycoplasma hyorhinis infection of pigs. Acta. Sci. Vet. 38(supl 1):209-215.

Siqueira F.M., Thompson C.E., Virginio V.G., Gonchoroski T., Reolon L., Almeida L.G., Fonseca M.M., Souza R., Prosdocimi F., Schrank I.S., Ferreira H.B. \& Vasconcelos A.T.R. 2013. New insights on the biology of swine respiratory tract mycoplasmas from a comparative genome analysis. BMC Genomics 14:175.

Sorensen V., Ahrens P., Barfod K., Feenstra A.A., Feld N.C., Friis N.F., Bille-Hansen V., Jensen N.E. \& Pedersen M.W. 1997. Mycoplasma hyopneumoniae infection in pigs: duration of the disease and evaluation of four diagnostic assays. Vet. Microbiol. 54:23-34.

Sorensen V., Jorsal S.E. \& Mousing J. 2006. Diseases of the respiratory system, p.149-177. In: Straw B.E., Zimmerman J.J., D’Allaire S., Taylor D.J. (Eds), Diseases of Swine. Iowa State University Press, Ames.

Souza N.N., Lobato Z.I.P. \& Guedes R.M.C. 2008. Estudo retrospectivo de diagnósticos de circovirose suína pela técnica de imunoistoquímica. Arqs Inst. Biológico, São Paulo, 75:521-525.

Stakenborg T., Vicca J., Butaye P., Imberechts H., Peeters J., De Kruif A., Haesebrouck F. \& Maes D. 2006. A multiplex PCR to identify porcine mycoplasmas present in broth cultures. Vet. Res. Commun. 30(3):239-247.

Stipkovits L., Nicolet J., Haldimann A. \& Frey J. 1991. Use of antibodies against the P36 protein of $M$. hyopneumoniae for the identification of the M. hyopneumoniae strain. Mol. Cell. Prob. 5:451-457.

Thacker E.L. \& Minion F.C. 2012. Mycoplasmosis, p.779-797. In: Zimmerman J.J., Karriker L.A., Ramirez A., Schwartz K.J., Stevenson G.W. (Eds), Diseases of Swine. Iowa State University Press, Ames.

Thacker E.L. 2004. Diagnosis of Mycoplasma hyopneumoniae. An. Health. Res. Rev. 5(2):317-320.

Vicca J., Stakenborg T., Maes D., Butaye P., Peeters J., De Kruif A. \& Haesebrouck F. 2003. Evaluation of virulence of Mycoplasma hyopneumoniae field isolates. Vet. Microbiol. 97:177-190.

Vincent L.L., Janke B.H., Paul P.S. \& Halbur P.G. 1997. A monoclonal-antibody-based immunohistochemical method for the detection of swine influenza virus in formalin-fixed, paraffin-embedded tissues. J. Vet. Diagn. Invest. 9:191-195. 